\title{
Leaf Characteristics and Yield Performance of Mungbean (Vigna radiata L.) Varieties under Different Levels of Shading
}

\author{
M. A. Hossain*, M. A. Hasan, S. Sikder and A. K. M. M. B. Chowdhury \\ Department of Crop Physiology and Ecology, Hajee Mohammad Danesh Science and \\ Technology University, Dinajpur, Bangladesh
}

*Corresponding author and Email: asmaulhstu@gmail.com

Received: 26 August 2017

Accepted: 22 December 2017

\begin{abstract}
An experiment was carried out to evaluate the leaf characteristics and yield performances of mungbean (Vigna radiata L.) under different light levels at the Crop Physiology and Ecology Research Field of Hajee Mohammad Danesh Science and Technology University, Dinajpur during March to June 2016. The experiment was laid out in a split plot design with three replications. Three light levels $\left(\mathrm{L}_{100}-100\right.$ $\%$ light intensity, $\mathrm{L}_{75^{-}} 75 \%$ light intensity and $\mathrm{L}_{50^{-}} 50 \%$ light intensity) were assigned in the main plots and four varieties (BARl Mung-6, BINA Mung-8, BINA Mung-5 and BU Mug-4) were assigned in subplots. Mosquito nets of different pore size were used for maintaining 75 and 50 percent light intensity. Leaf area was increased due to reduced light levels in all mugbean varieties but the increment was significant in BINA Mung-5 and BINA Mung-8 only at 75\% light intensity at 40 days after sowing and only in BARI Mung-6 with $\mathrm{L}_{50}$ and BU Mug-4 with $\mathrm{L}_{75}$ and $\mathrm{L}_{50}$ at 50 days after sowing. Due to reduced light levels, leaf dry weight was affected more in BINA Mung-5 and BU Mug4 than BARI Mung- 6 and BINA Mung-8. Leaf thickness was reduced under shade in all the mungbean varieties, except in BU Mug-4 at 75\% light intensity, and the reduction in leaf thickness was mainly due to the reduction in thickness of spongy layer. The palisade layer thickness was influenced insignificantly but spongy layer thickness was increased in BINA Mung-5 at 100\% light intensity. The grain yields $\left(\mathrm{t} \mathrm{ha}^{-1}\right)$ of BARI Mung- 6 and BINA Mung- 8 remained stable under partial shade condition but the grain yield of BINA Mung-5 and BU Mug-4 was reduced drastically under partial shade condition. Higher leaf dry weight, number of pods plant ${ }^{-1}$, seeds $\operatorname{pod}^{-1}$, and heavier grains in BARI Mung- 6 and BINA Mung- 8 contributed to the higher grain yield plant ${ }^{-1}$ under partial shade condition than in BINA Mung-5 and BU Mug-4.
\end{abstract}

Keywords: Mungbean, Light level, Spongy and palisade parenchyma and Yield.

\section{Introduction}

Mungbean (Vigna radiata L.) is one of the important pulse crops in our country. The agro ecological condition of Bangladesh is quite favorable for growing the crop. The demand of grain legumes is increasing day by day in
Bangladesh due to increase in consciousness of the nutrition of leguminous food among the common people (BBS, 2012). High population pressure and increased demand for food and other agricultural commodities have already started disruption of the natural resource base and environment in Bangladesh. The production 
capacity of our land is decreasing progressively due to intensive cropping with high yielding crop varieties and high input technologies. However, legume crops are considered as the contributor to improve the soil health worldwide.

Cereal-legume intercropping is a very common practice all over Bangladesh. However, most of the grain legumes are sensitive to partial shading and often suffer from low light stress caused by associated tall crops (Miranda-Abilay and Lantican, 1982). The legume canopy when intercropped with maize received about 30-50\% of the total incoming radiation at around 30-35 days of age of maize seedling (Polthanee and Changsri, 1999, Polthanee and Treloges, 2002). Light is the basic element that provides energy for photosynthesis, which is the basis of crop production. Shading causes decreasing of quantity and quality of the sun light intercept to the crop and it affects the productivity of the intercrops. Yield reduction by shading depends upon crop species as well as the degree of shading. The degree of shading is generally controlled by the nature, age and characteristics of upper storied crops. The yield of soybean was decreased by $25 \%$ under $47 \%$ shade cover in the field (Wahua and Miller, 1978) and it was decreased by $30 \%$ under $40 \%$ artificial shade (Lantican and Catedral, 1977). In contrast under $40 \%$ artificial shade the yield of mungbean was decreased by $70 \%$ (Lantican and Catedral, 1977). Shading leads to phenotypic change in their photosynthetic apparatus (Sundari, 2009). Shading reduced photosynthesis due to increase in stomatal and mesophyll resistance, transpiration, partitioning of biomass from vegetative parts to economic parts (Nygren and Killomaki, 1993). General adaptive responses of crop plant to low irradiance are the increase in leaf area ratio, chlorophyll content, leaf to stem mass and stem length and decrease in leaf thickness (Fujita et al., 1993; Singh, 1994).

However, responses of mungbean to change in light intensity may vary in different genotypes. Hence, developing mungbean variety adapted to low light condition is important in the context of intercropping between legume and non-legume crops in Bangladesh. The mungbean genotypes which have the least decrease in grain yield, number of pods per plant, per cent leaf $\mathrm{N}$ and total stem $\mathrm{N}$ could be the most tolerant mungbean genotypes to low light situation (Wahua and Miller, 1978). Therefore, the present investigation was conducted to find out potential shade tolerant mungbean genotypes with following objectives-

1. To estimate the effect of reduced light levels on vegetative growth and leaf characteristics of different mungbean varieties, and

2. To estimate the effect of reduced light levels on yield performances of different mungbean varieties.

\section{Materials and Methods}

The experiment was conducted at the Crop Physiology and Ecology Research Field, Hajee Mohammad Danesh Science and Technology University (HSTU), Dinajpur during the period from March to June 2016.

\subsection{Design and treatments}

The experiment was laid out in a split plot design with three replications. Three light treatments were assigned in the main plots and four varieties were arranged in the subplots. Three light levels were $\mathrm{L}_{100=} 100 \%$ light intensity (open field control), $\mathrm{L}_{75}=75 \%$ light intensity and $\mathrm{L}_{50}=50 \%$ light intensity), and the four mungbean varieties used in the sub-plots were BARI Mung-6, BINA Mung-8, BINA Mung-5 and BU Mug-4. $\mathrm{L}_{75}$ and $\mathrm{L}_{50}$ sunlight were maintained by using Mosquito nets.

\subsection{Data collection and analysis}

Three plants from each plot were randomly selected at 30, 40 and 50 days after sowing for collecting data on plant height, number of leaves, leaf area, leaf dry weight. Plant height was measured from base to the tip of the plant. Leaf area of all the green leaves was measured by leaf area meter (CI-202 AREA METER). At each sampling, plants were uprooted and separated into leaf, stem and root. After separating the 
different parts of the plants, individual component of the plants was oven dried at $70^{\circ} \mathrm{C}$ for at least 72 hours and weighed.

Leaf thickness was measured at 50 days after sowing. Firstly leaves were collected from the field and kept in ice-bag. Then crossed section was done and the thickness $(\mathrm{mm})$ of leaf with palisade and spongy layer in microscope was measured with used stage and ocular meter scale. For yield components of mungbean, ten plants of each of variety on each subplot were selected randomly from each replication at maturity stage of crop. At maturity, pods were harvested in different pickings. The harvesting of mungbean pods was started at 61 days after sowing and ended at 80 days after sowing. Yield of mungbean varieties was determined from the summation of all picking period and then converted to $\mathrm{tha}^{-1}$. Length of individual pod, pod number per plant, seeds per pod and 1000 seed weight were also recorded from the ten randomly selected plants of each plot.

The data were analyzed by partitioning the total variance with the help of computer using STATA program. The treatment means were compared using Tukey's Test.

\section{Results and Discussion}

\subsection{Plant height}

The interaction of light levels and mungbean varieties influenced the height of plant significantly at 30, 40 and 50 days after sowing (Table 1). In general the height of the plant increased with the advanced of time after sowing. At 30 days after sowing, the tallest plant $(30.33 \mathrm{~cm})$ was observed in BARI Mung- 6 with $50 \%$ light intensity which was statistically similar to those observed in BINA Mung -8 with $50 \%$ light intensity, BARI Mung- 6 and BINA Mung- 8 with $75 \%$ light intensity, BU Mug-4 with $100 \%$ light intensity, BU Mug-4 with $50 \%$ and $75 \%$ light intensity. The shortest plant $(25.50 \mathrm{~cm})$ was observed in BINA Mung-8 with $\mathrm{L}_{100}$ which was statistically similar to those observed in BARI Mung- 6 and BINA Mung- 5 with $\mathrm{L}_{100}$. The results also showed that the plant height was increased with the reduction in light levels compared to the control $\left(\mathrm{L}_{100}\right)$ in all the mungbean varieties. The increment due to low light stress was significant for BARI Mung-6 and BINA Mung-8, and it was insignificant for BINA Mung-5 and BU mug-4.

At 40 days after sowing, the tallest plant (44.63 $\mathrm{cm})$ was observed in BARI Mung-6 with $50 \%$ light intensity which was statistically similar to those observed in BINA Mung-5 with $\mathrm{L}_{100}$, BU Mug-4 with $50 \%$ and $75 \%$. The shortest plant $(30.43 \mathrm{~cm})$ was observed in BU Mug-4 with $\mathrm{L}_{100}$ which was statistically similar to those observed in BARI Mung-6 with $100 \%$ and $75 \%$ light intensity, BINA Mung-8 with $\mathrm{L}_{100}$ and BINA Mung-5 with $\mathrm{L}_{100}$. The results also revealed that the plant height was increased with the reduction in light levels compare to control $\left(\mathrm{L}_{100}\right)$ in all the mungbean varieties. The increment was significant only at 50 percent light intensity $\left(\mathrm{L}_{50}\right)$ in BARI Mung-6 and BINA Mung-8, whereas the increment was significant both 75 percent light intensity $\left(\mathrm{L}_{75}\right)$ and 50 percent light intensity $\left(\mathrm{L}_{50}\right)$ in BINA Mung-5 and BU mug-4.

At 50 days after sowing, the tallest plant (53.36 $\mathrm{cm}$ ) was observed in BU Mug-4 with 50\% light intensity which was statistically similar to those observed in BARI Mung-6 with 50\% light intensity, BINA Mung-8 with 50\% light intensity, BU Mug-4 with $75 \%$ light intensity. The shortest plant $(31.65 \mathrm{~cm})$ was observed in BINA Mung-8 with $\mathrm{L}_{100}$ which was statistically similar to those observed in BINA Mung-5 with $\mathrm{L}_{100}$. The results also showed that the plant height was increased with the reduction in light levels compare to control $\left(\mathrm{L}_{100}\right)$ in all mungbean varieties. The increment was significant both at 75 percent light intensity $\left(\mathrm{L}_{75}\right)$ and 50 percent light intensity $\left(\mathrm{L}_{50}\right)$. Similar results that shading effect increased plant height were also reported in mungbean by Islam (1995), Bashir (2002) and Islam (1996); in mungbean and chickpea by Ali (1998), in garden pea by Akhter et al. (2009c), in all legumes by Chiangmai et al. (2013) and in soybean by Bakhshy et al. (2013). 
Table1. Plant height of mungbean as influenced by light levels and varieties at different days after sowing (DAS)

\begin{tabular}{lcccc}
\hline Variety & Light level & \multicolumn{3}{c}{ Plant height $(\mathrm{cm})$} \\
\cline { 3 - 5 } & & $30 \mathrm{DAS}$ & $40 \mathrm{DAS}$ & $50 \mathrm{DAS}$ \\
\hline \multirow{3}{*}{ BARI Mung- 6 } & $\mathrm{L}_{100}$ & $26.03 \mathrm{~d}$ & $31.69 \mathrm{e}$ & $33.73 \mathrm{~cd}$ \\
& $\mathrm{~L}_{75}$ & $29.26 \mathrm{ab}$ & $36.72 \mathrm{de}$ & $39.23 \mathrm{~b}$ \\
& $\mathrm{~L}_{50}$ & $30.33 \mathrm{a}$ & $44.63 \mathrm{a}$ & $45.96 \mathrm{ab}$ \\
BINA Mung- 8 & $\mathrm{L}_{100}$ & $25.50 \mathrm{~d}$ & $36.47 \mathrm{de}$ & $31.65 \mathrm{e}$ \\
& $\mathrm{L}_{75}$ & $29.64 \mathrm{ab}$ & $38.41 \mathrm{bd}$ & $42.09 \mathrm{~b}$ \\
& $\mathrm{~L}_{50}$ & $30.19 \mathrm{a}$ & $39.33 \mathrm{bc}$ & $44.78 \mathrm{ab}$ \\
BINA Mung- 5 & $\mathrm{L}_{100}$ & $26.29 \mathrm{~cd}$ & $37.18 \mathrm{de}$ & $33.33 \mathrm{de}$ \\
& $\mathrm{L}_{75}$ & $27.98 \mathrm{bc}$ & $39.30 \mathrm{bc}$ & $37.25 \mathrm{c}$ \\
BU Mug- 4 & $\mathrm{L}_{50}$ & $28.13 \mathrm{bc}$ & $44.30 \mathrm{a}$ & $32.28 \mathrm{c}$ \\
& $\mathrm{L}_{100}$ & $29.03 \mathrm{ab}$ & $30.43 \mathrm{e}$ & $35.83 \mathrm{~cd}$ \\
& $\mathrm{~L}_{75}$ & $29.16 \mathrm{ab}$ & $43.57 \mathrm{ab}$ & $44.72 \mathrm{ab}$ \\
Level of significance & $\mathrm{L}_{50}$ & $29.29 \mathrm{ab}$ & $43.60 \mathrm{ab}$ & $53.36 \mathrm{a}$ \\
\hline
\end{tabular}

In a column, means followed by different letter(s) differed significantly by Tukey's test at $\mathrm{P} \leq 5 \%$ level of probability. $\mathrm{L}_{100}-100 \%$ light intensity (open field control); $\mathrm{L}_{75^{-}} 75 \%$ light intensity; $\mathrm{L}_{50}-50 \%$ light intensity

Table 2. Leaf number of mungbean as influenced by light levels and varieties at different days after sowing

\begin{tabular}{lcccc}
\hline Variety & Light level & \multicolumn{3}{c}{ Leaf number plant $^{-1}$} \\
\cline { 3 - 5 } & & 30 DAS & 40 DAS & 50 DAS \\
\hline \multirow{3}{*}{ BARI Mung- 6 } & $\mathrm{L}_{100}$ & 5.67 & 6.67 & 4.56 \\
& $\mathrm{~L}_{75}$ & 5.67 & 6.56 & 4.11 \\
& $\mathrm{~L}_{50}$ & 5.44 & 6.89 & 4.44 \\
BINA Mung- 8 & $\mathrm{L}_{100}$ & 5.00 & 6.56 & 4.00 \\
& $\mathrm{~L}_{75}$ & 5.22 & 6.44 & 3.89 \\
& $\mathrm{~L}_{50}$ & 4.89 & 6.56 & 4.78 \\
BINA Mung- 5 & $\mathrm{L}_{100}$ & 5.11 & 6.89 & 5.22 \\
& $\mathrm{~L}_{75}$ & 5.44 & 6.89 & 4.45 \\
& $\mathrm{~L}_{50}$ & 5.22 & 6.33 & 4.33 \\
BU Mug- 4 & $\mathrm{L}_{100}$ & 5.89 & 7.00 & 4.33 \\
& $\mathrm{~L}_{75}$ & 5.44 & 7.22 & 4.67 \\
\hline Level of significance & $\mathrm{L}_{50}$ & 5.33 & 7.00 & 5.22 \\
CV(\%) & & $\mathrm{NS}$ & $\mathrm{NS}$ & $\mathrm{NS}$ \\
\hline
\end{tabular}

In a column, means followed by different letter(s) differed significantly by Tukey's test at $\mathrm{P} \leq 5 \%$ level of probability. $\mathrm{L}_{100}-100 \%$ light intensity (open field control); $\mathrm{L}_{75^{-}} 75 \%$ light intensity; $\mathrm{L}_{50}-50 \%$ light intensity. 


\subsection{Number of leaves per plant}

The interaction of light levels and mungbean varieties showed that the leaf number was increased consecutively from 30 to 40 days after sowing thereafter decreased at 50 days after sowing (Table 2). At 30 days after sowing, the highest leaf number (5.89) was observed in BU Mug-4 with $100 \%$ light intensity and the lowest leaf number (4.89) was observed in BINA Mung- 8 with $50 \%$ light intensity. At 40 days after sowing, the highest leaf number (7.22) was observed in BU Mug-4 with 75\% light intensity and the lowest leaf number was observed in BINA Mung-5 with 50\% light intensity (6.33). At 50 days after sowing, the highest leaf number was observed both in BU Mug-4 with 50\% light intensity and BINA Mung-5 with 100\% light intensity (5.22), the lowest leaf number was observed in BINA Mung-8 with $75 \%$ light intensity (3.89).

The lower number of leaves per plant at the reduced light conditions may be due to lower production of photosynthates under low light conditions (Miah et al. 1999). Islam (1995) in mungbean and Crookston et al. (1975) in dry bean also found decreased leaf number under shade condition. Similar result of decrease in leaf number due to shading was found in all legumes by Chiangmai et al. (2013).

\subsection{Leaf area per plant}

Leaf area per plant was not influenced significantly by the interaction of light levels and mungbean varieties at 30 days after sowing but it was influenced significantly at 40 and 50 days after sowing (Table 3).

At 30 days after sowing, the highest leaf area per plant $\left(163.28 \mathrm{~cm}^{2}\right)$ was obtained in BARI Mung6 with $75 \%$ light intensity and the lowest leaf area per plant was obtained in BU Mug-4 with $50 \%$ light intensity $\left(96.29 \mathrm{~cm}^{2}\right)$. At 40 days after sowing, the highest leaf area per plant (482.44 $\mathrm{cm}^{2}$ ) was obtained in BINA Mung- 8 with $75 \%$ light intensity. The lowest leaf area per plant $\left(283.93 \mathrm{~cm}^{2}\right)$ was obtained in BU Mug-4 with $100 \%$ light intensity. The results revealed that the leaf area was increased due to reduced light levels in all mugbean varieties but the increment was significant in BINA Mung-5 and BINA Mung- 8 only with $75 \%$ light intensity.

At 50 days after sowing, the highest leaf area per plant was obtained in BARI Mung-6 with 50\% light intensity $\left(430.20 \mathrm{~cm}^{2}\right)$ which was followed by all the treatment combinations. The lowest leaf area per plant was obtained in BU Mug-4 with $100 \%$ light intensity $\left(173.38 \mathrm{~cm}^{2}\right)$ which was statistically similar in BARI Mung- 6 with $100 \%$ and $75 \%$ light intensity, BINA Mung-5 with $100 \%, 75 \%$ and $50 \%$ light intensity and BINA Mung-8 with $100 \%$ and 50\%light intensity. The results revealed that the leaf area was increased due to reduced light levels in all mungbean varieties but the increment was significant only in BARI Mung-6 with $\mathrm{L}_{50}$ and BU Mug-4 with $\mathrm{L}_{75}$ and $\mathrm{L}_{50}$.

Kubota and Hamid (1992) reported increased leaf area in mungbean and decreased leaf area in black gram under shade condition. Sundari (2009) found bigger leaves in tolerant genotypes than that of sensitive mungbean genotypes. Akhter et al. (2009b) investigated low light responses of eight garden pea genotypes. Among the genotype tested in the experiment leaf area (LA) increased with the reduction of PAR in P 30 and Local white but LA reduced in rest of the genotypes. Araki et al. (2014) also found a similar result that shading increased leaf area in greengram.

\subsection{Leaf dry weight per plant}

The interaction of light levels and mungbean varieties did not influence the leaf dry weight per plant significantly at 30 days after sowing but it was influenced significantly at 40 and 50 days after sowing (Table 4).

At 30 days after sowing, the highest leaf dry weight per plant $(0.56 \mathrm{~g})$ was obtained in BINA Mung-5 with $75 \%$ light intensity and the lowest leaf dry weight per plant $(0.33 \mathrm{~g})$ was obtained in BU Mug-4 with 50\% light intensity. 
Table 3. Leaf area of mungbean as influenced by light levels and varieties at different days after sowing

\begin{tabular}{lcccc}
\hline Variety & Light level & \multicolumn{3}{c}{ Leaf area plant ${ }^{-1}\left(\mathrm{~cm}^{2}\right)$} \\
\cline { 3 - 5 } & & $30 \mathrm{DAS}$ & $40 \mathrm{DAS}$ & $50 \mathrm{DAS}$ \\
\hline \multirow{3}{*}{ BARI Mung- 6 } & $\mathrm{L}_{100}$ & 133.82 & $307.69 \mathrm{c}$ & $186.10 \mathrm{e}$ \\
& $\mathrm{L}_{75}$ & 163.28 & $319.12 \mathrm{c}$ & $209.41 \mathrm{ce}$ \\
& $\mathrm{L}_{50}$ & 125.55 & $403.41 \mathrm{ac}$ & $430.20 \mathrm{a}$ \\
BINA Mung- 8 & $\mathrm{L}_{100}$ & 124.29 & $289.91 \mathrm{c}$ & $218.53 \mathrm{be}$ \\
& $\mathrm{L}_{75}$ & 152.38 & $482.44 \mathrm{a}$ & $280.64 \mathrm{~cd}$ \\
& $\mathrm{~L}_{50}$ & 148.13 & $344.73 \mathrm{bc}$ & $232.01 \mathrm{be}$ \\
BINA Mung- 5 & $\mathrm{L}_{100}$ & 116.92 & $312.52 \mathrm{c}$ & $194.04 \mathrm{e}$ \\
& $\mathrm{L}_{75}$ & 135.69 & $461.96 \mathrm{ab}$ & $205.39 \mathrm{de}$ \\
\multirow{3}{*}{ BU Mug- 4 } & $\mathrm{L}_{50}$ & 116.78 & $303.68 \mathrm{c}$ & $207.19 \mathrm{ce}$ \\
& $\mathrm{L}_{100}$ & 134.06 & $283.93 \mathrm{c}$ & $173.38 \mathrm{e}$ \\
\hline Level of significance & $\mathrm{L}_{75}$ & 133.67 & $409.60 \mathrm{ac}$ & $291.80 \mathrm{~b}$ \\
CV(\%) & $\mathrm{L}_{50}$ & 96.29 & $377.68 \mathrm{ac}$ & $278.79 \mathrm{bd}$ \\
\hline
\end{tabular}

In a column, means followed by different letter(s) differed significantly by Tukey's test at $\mathrm{P} \leq 5 \%$ level of probability. $\mathrm{L}_{100}-100 \%$ light intensity (open field control); $\mathrm{L}_{75^{-}} 75 \%$ light intensity; $\mathrm{L}_{50}-50 \%$ light intensity.

Table 4. Leaf dry weight of mungbean as influenced by light levels and varieties at different days after sowing

\begin{tabular}{lcccc}
\hline Variety & Light level & \multicolumn{3}{c}{ Leaf dry weight $(\mathrm{g})$} \\
\cline { 3 - 5 } & & $30 \mathrm{DAS}$ & $40 \mathrm{DAS}$ & $50 \mathrm{DAS}$ \\
\hline \multirow{3}{*}{ BARI Mung- 6 } & $\mathrm{L}_{100}$ & 0.45 & $1.61 \mathrm{ab}$ & $1.34 \mathrm{~b}$ \\
& $\mathrm{~L}_{75}$ & 0.53 & $1.29 \mathrm{ac}$ & $1.42 \mathrm{~b}$ \\
& $\mathrm{~L}_{50}$ & 0.44 & $1.71 \mathrm{a}$ & $1.72 \mathrm{a}$ \\
BINA Mung- 8 & $\mathrm{L}_{100}$ & 0.42 & $1.46 \mathrm{ac}$ & $1.42 \mathrm{~b}$ \\
& $\mathrm{~L}_{75}$ & 0.46 & $1.56 \mathrm{ab}$ & $1.42 \mathrm{~b}$ \\
& $\mathrm{~L}_{50}$ & 0.45 & $1.54 \mathrm{ac}$ & $1.32 \mathrm{~b}$ \\
BINA Mung- 5 & $\mathrm{L}_{100}$ & 0.48 & $1.37 \mathrm{ac}$ & $1.85 \mathrm{a}$ \\
& $\mathrm{L}_{75}$ & 0.56 & $1.61 \mathrm{ab}$ & $1.79 \mathrm{a}$ \\
& $\mathrm{L}_{50}$ & 0.35 & $1.05 \mathrm{c}$ & $1.27 \mathrm{~b}$ \\
BU Mug- 4 & $\mathrm{L}_{100}$ & 0.55 & $1.46 \mathrm{ac}$ & $1.66 \mathrm{~b}$ \\
& $\mathrm{~L}_{75}$ & 0.52 & $1.66 \mathrm{a}$ & $1.34 \mathrm{~b}$ \\
\hline Level of significance & $\mathrm{L}_{50}$ & 0.33 & $1.20 \mathrm{bc}$ & $1.27 \mathrm{~b}$ \\
CV(\%) & & $\mathrm{NS}$ & $* *$ & 4.34 \\
\hline
\end{tabular}

In a column, means followed by different letter(s) differed significantly by Tukey's test at $\mathrm{P} \leq 5 \%$ level of probability. $\mathrm{L}_{100}-100 \%$ light intensity (open field control); $\mathrm{L}_{75^{-}}-75 \%$ light intensity; $\mathrm{L}_{50}-50 \%$ light intensity. 
At 40 days after sowing, the highest leaf dry weight per plant $(1.71 \mathrm{~g})$ was obtained in BARI Mung-6 with 50\% light intensity which was statistically similar in all treatment combinations except BINA Mung-5 and BU Mug- 4 with 50\% light intensity. The lowest leaf dry weight per plant $(1.05 \mathrm{~g})$ was obtained in BINA Mung-5 with $50 \%$ light intensity which was statistically similar in BU Mug- 4 with $100 \%$ and $50 \%$ light intensity, BARI Mung-6 with $75 \%$ light intensity, BINA Mung-5 with $100 \%$ light intensity, BINA Mung-8 with $100 \%$ and $50 \%$ light intensity.

At 50 days after sowing, the highest leaf dry weight per plant $(1.85 \mathrm{~g})$ was obtained in BINA Mung-5 with $100 \%$ light intensity which was statistically similar in BINA Mung-5 with $75 \%$ light intensity and BARI Mung-6 with 50\% light intensity. The lowest leaf dry weight per plant $(1.27 \mathrm{~g})$ was obtained both in BINA Mung-5 and BU Mug- 4 with 50\% light intensity which was statistically similar in all treatment combinations except BARI Mung-6 with 50\% light intensity, BINA Mung-5 with $100 \%$ and $75 \%$ light intensity.

The overall results in leaf dry weight showed that BINA Mung-5 and BU Mug-4 affected more than BARI Mung-6 and BINA Mung-8. Islam et al. (1993) and Laosuwan et al. (1991) reported lower specific leaf weight in mungbean. Akhter et al. (2009b) reported lower specific leaf weight in garden pea under shade. Rao and Mittra (1988), Marler et al. (1994) and Singh (1994) found lower leaf dry weight in legume crops under shade. Similar result was found in all legumes by Chiangmai et al. (2013). Araki et al. (2014) also found similar result in greengram.

\subsection{Thickness of palisade and spongy layer}

Light levels and mungbean varieties interacted significantly to influence the thickness of spongy layer but the thickness of palisade layer was not influenced significantly by the interaction effect of light levels and mungbean varieties (Table 5).

Table 5. Thickness of spongy and palisade layer of mungbean as influenced by light levels and mungbean varieties

\begin{tabular}{lccc}
\hline Variety & Light level & $\begin{array}{c}\text { Thickness of spongy layer } \\
(\mathrm{mm})\end{array}$ & $\begin{array}{c}\text { Thickness of palisade layer } \\
(\mathrm{mm})\end{array}$ \\
\hline \multirow{3}{*}{ BARI Mung- 6} & $\mathrm{~L}_{100}$ & $0.10 \mathrm{ab}$ & 0.13 \\
& $\mathrm{~L}_{75}$ & $0.10 \mathrm{ab}$ & 0.13 \\
& $\mathrm{~L}_{50}$ & $0.07 \mathrm{~b}$ & 0.12 \\
BINA Mung- 8 & $\mathrm{~L}_{100}$ & $0.09 \mathrm{ab}$ & 0.11 \\
& $\mathrm{~L}_{75}$ & $0.06 \mathrm{~b}$ & 0.12 \\
& $\mathrm{~L}_{50}$ & $0.10 \mathrm{ab}$ & 0.10 \\
BINA Mung- 5 & $\mathrm{L}_{100}$ & $0.13 \mathrm{a}$ & 0.10 \\
& $\mathrm{~L}_{75}$ & $0.11 \mathrm{ab}$ & 0.13 \\
& $\mathrm{~L}_{50}$ & $0.09 \mathrm{ab}$ & 0.10 \\
BU Mug- 4 & $\mathrm{L}_{100}$ & $0.09 \mathrm{ab}$ & 0.11 \\
& $\mathrm{~L}_{75}$ & $0.10 \mathrm{ab}$ & 0.12 \\
\hline Level of significance & $\mathrm{L}_{50}$ & $0.08 \mathrm{ab}$ & 0.10 \\
CV(\%) & & $*$ & $\mathrm{NS}$ \\
\hline
\end{tabular}

In a column, means followed by different letter(s) differed significantly by Tukey's test at $\mathrm{P} \leq 5 \%$ level of probability. $\mathrm{L}_{100}-100 \%$ light intensity (open field control), $\mathrm{L}_{75^{-}} 75 \%$ light intensity, $\mathrm{L}_{50} \quad-\quad 50 \%$ light intensity. 
Table 6. Yield attributes of mungbean as influenced by light levels and varieties

\begin{tabular}{lcccc}
\hline Variety & Light level & No.of pod plant & No. of seed pod & $\begin{array}{c}1000 \text { seed wt }^{-1} \\
\left(\mathrm{~g} \mathrm{plot}^{-1}\right)\end{array}$ \\
\hline & $\mathrm{L}_{100}$ & $10.00 \mathrm{a}$ & $8.57 \mathrm{ef}$ & $45.20 \mathrm{~b}$ \\
BARI Mung- 6 & $\mathrm{L}_{75}$ & $9.57 \mathrm{ab}$ & $9.15 \mathrm{bc}$ & $47.23 \mathrm{a}$ \\
& & $(-4.30)$ & $(6.77)$ & $(2.03)$ \\
& $\mathrm{L}_{50}$ & $9.27 \mathrm{ab}$ & $9.03 \mathrm{bd}$ & $44.00 \mathrm{~b}$ \\
& & $(-7.30)$ & $(5.37)$ & $(-2.65)$ \\
BINA Mung- & $\mathrm{L}_{100}$ & $8.97 \mathrm{ab}$ & $8.08 \mathrm{~g}$ & $45.28 \mathrm{~b}$ \\
& $\mathrm{~L}_{75}$ & $9.63 \mathrm{ab}$ & $8.62 \mathrm{ef}$ & $44.09 \mathrm{~b}$ \\
& & $(7.35)$ & $(6.68)$ & $(-2.63)$ \\
& $\mathrm{L}_{50}$ & $9.07 \mathrm{ab}$ & $8.40 \mathrm{fg}$ & $45.11 \mathrm{~b}$ \\
& & $(1.11)$ & $(3.96)$ & $(0.38)$ \\
BINA Mung- 5 & $\mathrm{L}_{100}$ & $9.90 \mathrm{a}$ & $9.20 \mathrm{bc}$ & $38.26 \mathrm{~d}$ \\
& $\mathrm{~L}_{75}$ & $7.03 \mathrm{de}$ & $9.32 \mathrm{~b}$ & $38.91 \mathrm{~d}$ \\
& & $(-28.99)$ & $(1.30)$ & $(1.70)$ \\
& $\mathrm{L}_{50}$ & $7.70 \mathrm{~cd}$ & $8.95 \mathrm{~cd}$ & $40.49 \mathrm{c}$ \\
& & $(-22.22)$ & $(-2.72)$ & $(5.83)$ \\
BU Mug- 4 & $\mathrm{L}_{100}$ & $8.93 \mathrm{ac}$ & $9.20 \mathrm{bc}$ & $45.40 \mathrm{~b}$ \\
& $\mathrm{~L}_{75}$ & $8.27 \mathrm{bd}$ & $9.73 \mathrm{a}$ & $41.87 \mathrm{c}$ \\
& & $(-7.39)$ & $(5.76)$ & $(-9.85)$ \\
Level of significance & & $6.07 \mathrm{e}$ & $8.78 \mathrm{de}$ & $41.65 \mathrm{c}$ \\
CV (\%) & $\mathrm{L}_{50}$ & $(-32.03)$ & $(-4.56)$ & $(-8.26)$ \\
\hline
\end{tabular}

In a column, means followed by different letter(s) differed significantly by Tukey'stest at $\mathrm{P} \leq 5 \%$ level of probability. $\mathrm{L}_{100}-100 \%$ light intensity (open field control), $\mathrm{L}_{75^{-}} 75 \%$ light intensity, $\mathrm{L}_{50}-50 \%$ light intensity.

The highest spongy layer thickness $(0.13 \mathrm{~mm})$ was recorded in BINA Mung-5 with 100\% light intensity which was statistically identical in all treatment combinations except BARI Mung-6 with $50 \%$ light intensity and BINA Mung-8 with $75 \%$ light intensity. The lowest spongy layer thickness $(0.06 \mathrm{~mm})$ was recorded in BINA Mung-8 with $75 \%$ light intensity which was statistically identical to those recorded in all other treatment combinations except BINA Mung-5 with $100 \%$ light intensity.

The results revealed that leaf thickness was reduced under shade in all varieties except in BU Mug-4 with $75 \%$ light intensity and this reduction in leaf thickness was due to reduced thickness of spongy layer. Crookston et al.
(1975) reported that shading reduced leaf thickness of bean. Similar result of shading induced reduced thickness was found in all legumes by Chiangmai et al. (2013) and Araki et al. (2014).

\subsection{Yield and yield contributing characters}

The interaction effect of light levels and mungbean varieties on number of pod per plant was significant (Table 6). The highest number of pod per plant (10.00) was observed in BARI Mung-6 with $100 \%$ light intensity which was statistically similar to those recorded in BINA Mung-5 with $100 \%$ light intensity, BINA Mung8 with $100 \%, 75 \%$ and $50 \%$ light intensity, BARI Mung-6 with $75 \%$ and $50 \%$ light intensity and BU Mug-4 with 100\% light 
intensity. The lowest number of pod per plant (6.07) was observed in BU Mug-4 with 50\% light intensity which was statistically similar to that recorded in BINA Mung-5 with $75 \%$ light intensity.

Percent change from $\mathrm{L}_{100}$ values indicated that the number of pod per plant was reduced with reduction in light levels in BARI Mung-6, BINA Mung-5 and BU Mug-4 but it was even increased in BINA Mung-8 under low light levels. The reduction in number of pod per plant with the reduction of light levels was more in BINA Mung-5 and BU Mug-4 than that in BARI Mung-6.

\subsection{Number of seeds pod ${ }^{-1}$}

The interaction effect of light levels and mungbean varieties on number of seed per pod was significant (Table 6). The highest number of seed per pod (9.73) was recorded in BU Mug-4 with $75 \%$ light intensity which was followed by all others treatment combinations. The lowest number of seed per pod (8.08) was recorded in BINA Mung-8 with $100 \%$ light intensity which was statistically similar to that recorded in BINA Mung-8 with 50\% light intensity (8.40).

Percent change from control $\left(\mathrm{L}_{100}\right)$ values indicated that the number of seed per pod was increased with reduction in light levels in BARI Mung-6 and BINA Mung-8. On the other hand, in BINA Mung-5and BU Mug-4 it was increased in $75 \%$ light intensity but decreased in $75 \%$ light intensity.

\subsection{Thousand Seeds weight plot ${ }^{-1}$}

The interaction effect of light levels and mungbean varieties on 1000-seed weight was significant (Table 6). The heaviest 1000-seed weight (47.23 g) was observed in BARI Mung-6 at $\mathrm{L}_{75}$ which was followed by all others treatment combinations. The lowest 1000-seed weight (38.26 g) was observed in BINA Mung-5 at $\mathrm{L}_{100}$ which was statistically similar to that recorded in BINA Mung-5 at $\mathrm{L}_{75}(38.91 \mathrm{~g})$. The results in thousand seeds weight also revealed that it was increased or remained more or less unchanged due to low light conditions in BARI Mung-6, BINA Mung- 8 and BINA Mung-5 but it was reduced with the reduction in light levels in BU Mug-4.

\subsection{Grain yield}

The interaction effect of light levels and mungbean varieties on grain yield per plant was significant (Table 7). The highest grain yield per plant (3.07 g) was observed in BARI Mung-6 both at $\mathrm{L}_{100}$ and $\mathrm{L}_{75}$ which was statistically similar to those obtained from BINA Mung-8 at $\mathrm{L}_{100}(3.01 \mathrm{~g})$, BU Mug-4 at $\mathrm{L}_{100}(3.00 \mathrm{~g})$, BARI Mung-6 at $\mathrm{L}_{50}(2.89 \mathrm{~g})$ and BINA Mung-5 at $\mathrm{L}_{100}$ $(2.89 \mathrm{~g})$. The lowest grain yield per plant $(2.02$ g) was observed in BU Mug-4 at $\mathrm{L}_{50}$. The results in grain yield plant ${ }^{-1}$ also revealed that it was remained unchanged or decreased with the reduction in light levels but the reduction in grain yield plant ${ }^{-1}$ more in BINA Mung-5 and BU Mug-4 than in BARI Mung-6 and BINA Mung-8.

The interaction of light levels and mungbean varieties influenced the grain yield $\left(\mathrm{t} \mathrm{ha}^{-1}\right)$ significantly (Table 7). The highest grain yield per hectare $\left(0.94 \mathrm{t} \mathrm{ha}^{-1}\right)$ was recorded in BU Mug-4 with $100 \%$ light intensity which was statistically similar to those recorded in BINA Mung-5 with $100 \%$ light intensity $\left(0.90 \mathrm{t} \mathrm{ha}^{-1}\right)$. The lowest grain yield per hectare $\left(0.52 \mathrm{t} \mathrm{ha}^{-1}\right)$ was recorded in BU Mug-4 with 50\% light intensity which was statistically similar to that observed in BINA Mung-5 with 50\% light intensity $\left(0.60 \mathrm{t} \mathrm{ha}^{-1}\right)$. Other treatment combinations provided moderate grain yield.

The results in grain yield per hectare also indicated that the yield was remained statistically unchanged due to lower light levels in BARI Mung- 6 and BINA Mung- 8 but in BINA Mung5 and BU Mug-4, the grain yield was reduced with the reduction in light levels.

Lantican and Catedral (1977), Laosuwan et al. (1992) and Miranda-Abilay and Lantican (1982) observed lower seed yield for shaded grown mungbean plant. 
Table 7. Grain yield of mungbean as influenced by light levels and varieties

\begin{tabular}{|c|c|c|c|}
\hline Variety & Light level & $\begin{array}{l}\text { Grain yield } \\
\left(\mathrm{g} \text { plant }{ }^{-1}\right)\end{array}$ & $\begin{array}{l}\text { Grain yield } \\
\left(\text { tha }^{-1}\right)\end{array}$ \\
\hline \multirow{4}{*}{ BARI Mung- 6} & $\mathrm{~L}_{100}$ & $3.07 \mathrm{a}$ & 0.82 ce \\
\hline & $\mathrm{L}_{75}$ & $3.07 \mathrm{a}$ & $0.79 \mathrm{de}$ \\
\hline & & $(0.00)$ & \\
\hline & $\mathrm{L}_{50}$ & $\begin{array}{c}2.89 \mathrm{ad} \\
(-5.86)\end{array}$ & 0.82 ce \\
\hline \multirow{3}{*}{ BINA Mung- 8} & $\mathrm{~L}_{100}$ & $3.01 \mathrm{ac}$ & $0.85 \mathrm{bc}$ \\
\hline & $\mathrm{L}_{75}$ & $\begin{array}{c}2.86 \mathrm{bd} \\
(-4.98)\end{array}$ & $0.87 \mathrm{bc}$ \\
\hline & $\mathrm{L}_{50}$ & $\begin{array}{l}2.84 \mathrm{~cd} \\
(-5.64)\end{array}$ & $0.86 \mathrm{bc}$ \\
\hline \multirow{4}{*}{ BINA Mung- 5} & $\mathrm{~L}_{100}$ & $2.89 \mathrm{ad}$ & $0.90 \mathrm{ab}$ \\
\hline & $\mathrm{L}_{75}$ & $2.47 \mathrm{e}$ & $0.76 \mathrm{e}$ \\
\hline & & $(-14.53)$ & \\
\hline & $\mathrm{L}_{50}$ & $\begin{array}{c}2.28 \mathrm{e} \\
(-21.11)\end{array}$ & $0.60 \mathrm{~g}$ \\
\hline \multirow{3}{*}{ BU Mug- 4} & $\mathrm{~L}_{100}$ & $3.00 \mathrm{ac}$ & $0.94 \mathrm{a}$ \\
\hline & $\mathrm{L}_{75}$ & $\begin{array}{l}2.75 \mathrm{~d} \\
(-8.33)\end{array}$ & $0.61 \mathrm{f}$ \\
\hline & $\mathrm{L}_{50}$ & $\begin{array}{c}2.02 \mathrm{f} \\
(-32.67)\end{array}$ & $0.52 \mathrm{~g}$ \\
\hline \multirow{2}{*}{\multicolumn{2}{|c|}{$\begin{array}{l}\text { Level of significance } \\
\mathrm{CV}(\%)\end{array}$}} & $* *$ & $* *$ \\
\hline & & 2.66 & 3.43 \\
\hline
\end{tabular}

In a column, means followed by different letter(s) differed significantly by Tukey's test at $\mathrm{P} \leq 5 \%$ level of probability. $\mathrm{L}_{100}-100 \%$ light intensity (open field control), $\mathrm{L}_{75^{-}}-75 \%$ light intensity, $\mathrm{L}_{50}-50 \%$ light intensity.

Polthanee et al. (2011) showed that grain yield of soybean was significantly $(\mathrm{p}<0.05)$ decreased under the low light intensity at $30 \%$ of natural light both in wet and dry season. Akhter et al. (2009c) reported reducing the light intensity from $100 \%$ to $25 \%$ exerted variable quantity of reduction of dry seed yield plant ${ }^{-1}$ in different genotypes and the reduction of seed yield plant ${ }^{-1}$ was attributed to poor pod plant $^{-1}$, fewer seed pod $^{-1}$ and smaller weight of seed. Islam (1995) found pods per plant decreased with the increase of shading. . Khan et al. (2012) also reported reduced number of pods plant $^{-1}$, number of grains pod $^{-1}$, 1000-grain weight, biological yield and grain yield of mungbean in plots intercropping with maize compared to sole mungbean.

\section{Conclusions}

Leaf area was increased due to reduced light levels in all mugbean varieties but the increment was significant in BINA Mung-5 and BINA Mung- 8 only at $75 \%$ light intensity at 40 days after sowing and only in BARI Mung- 6 with $\mathrm{L}_{50}$ and BU Mug- 4 with $\mathrm{L}_{75}$ and $\mathrm{L}_{50}$ at 50 days after sowing. Due to reduced light levels, leaf dry weight was affected more in BINA Mung-5 and BU Mug- 4 than BARI Mung-6 and BINA Mung-8.Leaf thickness was reduced under shade in all the mungbean varieties except in BU Mug4 at $75 \%$ light intensity, and the reduction in leaf thickness was mainly due to the reduction in thickness of spongy layer. The palisade layer thickness was insignificantly influenced but 
spongy layer thickness was increased in BINA Mung-5 at $100 \%$ light intensity. The grain yield $\left(\mathrm{t} \mathrm{ha}{ }^{-1}\right.$ ) of BARI Mung-6 and BINA Mung-8 remained stable under partial shade condition but the grain yield of BINA Mung-5 and BU Mug-4 was reduced drastically under partial shade condition. Higher leaf dry weight, number of pods plant ${ }^{-1}$ seeds pod $^{-1}$, and heavier grains in BARI Mung- 6 and BINA Mung- 8 contributed to the higher grain yield plant ${ }^{-1}$ under partial shade condition than in BINA Mung-5 and BU Mug-4.

\section{References}

Araki, T. T. T. O. and Kubota, F. 2014. Effects of Shading on Growth and Photosynthetic Potential of Greengram (Vigna radiata L. Wilczek) Cultivars. Environment Control Biology, 52 (4): 227-231.

Akhter, N., Rahman, M. M., Hasanuzzaman M. and Nahar, K. 2009b. Plant Characters and Seed Yield of Garden Pea under Different Light Intensity. AmericanEurasian Journal of Agronomy 2 (3): 152155.

Akhter, N., Rahman, M. M., Hasanuzzaman M. and Nahar, K. 2009c. Physiological Response of Garden Pea (Pisum sativum L.) grown under different light environment. Botany Resource International, 2 (4): 304-309.

Ali, M. A. 1998. Growth and yield of mungbean genotype under sun and shade conditions. MS Thesis, BSMRAU, Gazipur, Bangladesh.

Bakhshy, J., Ghassemi-Golezani, K., ZehtabSalmasi, S. and Moghaddam, M. 2013. Effects of Water Deficit and Shading on Morphology and Grain Yield of Soybean (Glycine max L.). Technical Journal of Engineering and Applied Sciences, 39-43 pp.

BBS. 2012. Year book of agricultural statistics2011. Bangladesh Bureau of Statistics, Statistics Division, Ministry of Planning,
Government of the people's Republic of Bangladesh.

Bashir, M.M. 2002. Performance of blackgram and mungbean varieties under different light levels. M.S. Thesis, BSMRAU, Bangladesh.

Chiangmai, P. N., Pootaeng-on, Y. and Khewaram, T. 2013 .Evaluation of the Shade Tolerance of Moth Bean (Vigna aconitifolia) and Two Tropical Legume Species. Silpakorn University Science \& Technology Journal, 7(1): 19-31

Crookston, R. K., Treharne, K. J., Ludofrd, P. and Ozbur, J. L. 1975. Response of beans to shading. Crop Science, 15: 4 12-416.

Fujita, K., Matsamoto, K., Buda, G.K.O. and Ogata, S. 1993.Effect of shading on growth and Di-nitrogen fixation of Kudzce and tropical pasture legumes. Soil Science Plant nutrition, 39(1): 43-54.

Islam, M. S. 1996. Effect of shading on gas cxchange characteristics and productivity of mungbean and blackgram. An $M S$ Thesis, Department of Agronomy, IPSA, Gazipur, Bangladesh.

Islam, S. M. T., Kubota, F., Mollah, M. F. H. and Agata, W.1993. Effect of Shading on the Growth and Yield of Mungbean (Vigna radiata L.) wikzel. Journal of Agronomy and Crop Science, 171: 274-278.

Islam, S. M. 1995. Effect of shading on gas cxchange charactcristics and productivity of mungbean and blackgram. MS thesis, IPSA, Gazipur, Bangladesh.

Khan, M. A., Naveed, K., Ali, K., Ahmed, B. and Jan, S. 2012. Impact of mungbeanmaize intercropping on growth and yield of mungbean. Pakistan Journal Weed Science Resource, 18(2): 191-200.

Kubota, F. and Hamid, A. 1992. Comparative analysis of dry matter production and photosynthesis between mungbean (Vigna radiate (L.) Wilczek) and blackgram ( $V$. 
mungo (L.) Hopper) grown in different light intensity. Journal Faculty Agriculture Kyashu University, 37: 71-80

Lantican, R. M. and Catedral, I. G. 1977. Evaluation of legumes for adaptation to intensive cropping systems. I. Mungbean, Vigna radiata (L,) wikzel. Philippine Journal of Crop Science, 2: 62-66.

Laosuwan, P., Saengpratoom, S., Kaloowong, S. and Thongsomsni, A.1992. Breeding mungbean for shade tolerance, In "Proceedings of mungbean meeting", Chiang Mai Thailand, 95-100 pp.

Laosuwan, P., Saengpratoom, S., Kalawong, S. and Thongsomsri, A. 1991. Breeding mungbean for shading tolerance proceedings of the mungbean meeting. Chiang Mai Thailand, February 23-24, 1990.

Marler, T. E., Schaffer-B, B. and crane, J.H. 1994. Development light level affects growth, morphology and leaf physiology of young carambola trees. Journal American Society Horticultural Science, 119 (4): 711-718.

Miah, M. G., Rahman, M. A. and Haque, M.M. 1999. Performance of onion under different reduced light levels for Agroforestry and Intercroping systems. Bulletin of Tropical Agriculture, 22.

Miranda-Abilay, R. and Lantican, R. M. 1982. Characters associated with yield performance of grain legume crops under partial shaded condition I. Mungbean (Vigna radiata). Philippine Journal Crop Science, 7(2): 88-93.

Nygren, M. and Killomaki, S. 1993.Effect of shading on leaf structure and photosynthesis in young birches. Forest Ecology Management, 7(2): 119-132.

Polthanee, A. and Changsri, R.1999. Effect of planting dates of mungbean on growth and yield in corn mungbean relay cropping under rainfed conditions in an up-land area of Northeastern Thailand. Thai Journal of Agricultural Science, 32: 187-196.

Polthanee, A. and Treloges, V. 2002. Growth and yield of mungbean cultivars in mungbean-corn relay inter-cropping systems. Journal of International Society for Southeast Asian Agricultural Science, 8: $1-14$

Polthanee, A. and Treloges, V. 2003. Growth, yield and land use efficiency of corn and legumes grown under intercropping systems. Plant Production Science, 6: 139-146.

Polthanee, A., Promsaena, K. Laoken, A. 2011. Influence of low light intensity on growth and yield of four soybean cultivars during wet and dry seasons of Northeast Thailand. Agricultural Science, 2(2): 6167.

Rao, L. J. and Mittara, B.N. 1988. Growth and yield of peanut as influenced degree and duration of shading. Journal of Agronomy and Crop Science, 160: 260-265.

Singh, S. 1994. Physiological response of different crop species to low light stress. Indian Journal of Plant Physiology, 37(3): 147-151.

Sundari, T. 2009. Morphological and physiological characteristics of shading tolerant and sensitive mungbean genotypes. HAYATI Journal of Biological Science, 16(4): 127-134.

Wahua, T.A.T. and Miller, D.A. 1978. Effects of shading on the $\mathrm{N}_{2}$-fixation, yield, and plant composition of field-grown soybeans. Agronomy Journal, 70: $387-$ 392. 